Gut, 1986, 27, 1227-1131

\title{
Gastro-oesophageal reflux in the irritable bowel syndrome
}

\author{
H L SMART, * D A NICHOLSON, AND M ATKINSON \\ From the Department of Surgery, University Hospital, Queens Medical Centre, Nottingham
}

\begin{abstract}
SUMmARY Symptomatic assessment and oesophageal investigations were done in 25 consecutive patients with the irritable bowel syndrome attending a gastroenterological clinic. Symptoms of gastro-oesophageal reflux, dysphagia, and a globus sensation were significantly commoner than in a control group of fracture clinic patients. Ambulatory oesophageal $\mathrm{pH}$ monitoring showed clearly abnormal reflux in 11 of 22 patients $(50 \%)$. Nine patients had macroscopic endoscopic changes and a further 11 biopsy changes alone, of oesophagitis which was thus present in $80 \%$ overall. Lower oesophageal sphincter pressure was significantly less in irritable bowel patients than in age and sex matched controls, but upper oesophageal sphincter pressure was comparable in the two groups and disordered peristalsis was was not found. Oesophageal symptoms in the irritable bowel syndrome are mainly caused by gastro-oesophageal reflux predisposed to by a subnormal lower oesosphageal sphincter pressure, rather than by oesophageal spasm.
\end{abstract}

The irritable bowel syndrome is a common gastrointestinal disorder in which oesophageal symptoms ${ }^{12.3}$ and disordered oesophageal peristalsis ${ }^{4}$ have been reported. Oesophageal spasm analogous to colonic spasm has been described in the irritable bowel but previous studies on gastrointestinal motility in this syndrome, however, have not always shown reproducible abnormalities which correlate with patients symptoms. ${ }^{5}$ Others have found symptoms suggestive of gastro-oesophageal reflux $x^{3}$ but uncertainty remains about the basis and the frequency of oesophageal symptoms in the irritable bowel syndrome.

This study was done to assess the nature and frequency of oesophageal symptoms, motility disorder, and gastro-oesophageal reflux in the irritable bowel syndrome.

\section{Methods}

PATIENTS

Twenty five consecutive patients (15 women) attending a gastrointestinal clinic with the irritable bowel syndrome were studied. Their mean age was 39 years (range 24-61 years). Patients were con-

Address for correspondence: Professor M Atkinson. Department of Surgerv. Floor E. West Block. University Hospital. Nottingham NG7 2UHI.

*Present address: Dept of Medicine. Royal Hallamshire Ilospital. Sheffield SI0 2JF

Received for publication + February 1986 sidered to have the irritable bowel syndrome if they complained of abdominal pain and disordered bowel habit of at least one years duration. The symptoms found by Manning et at to be common in irritable bowel syndrome were used as useful confirmation of the presence of this condition. In all, clinical examination, sigmoidoscopy and rectal biopsy, stool culture, haematological and biochemical indices, and barium enema gave normal results.

One hundred and fifty age and sex matched patients drawn from the hospital fracture clinic were used as controls for the assessment of oesophageal symptoms. The control group used for comparison in oesophageal manometry consisted of 25 age and sex matched subjects without oesophageal symptoms.

\section{OESOPHAGEAL SYMPTOMS}

Gastro-oesophageal reflux (heartburn, acid regurgitation, or both), dysphagia and globus sensation were assessed by a physician administered questionnaire in the irritable bowel syndrome patients. In the control patients assessment was also by questionnaire, in which the above symptoms were described in simple terms. Previous work in this unit has shown the validity of the different methods described above in the assessment of symptoms of gastro-oesophageal reflux. Comparison between the two groups was done using $\chi^{2}$ or two tailed Fisher exact probability test as appropriate. 
UPPER GASTROINTESTINAL ENDOSCOPY

This was performed by a single endoscopist (HLS) using standard topical anaesthesia and iv benzodiazepine sedation. Careful inspection of the oesophagus was undertaken and any macroscopic abnormality noted and biopsied. If no lesion was seen then at least three biopsies were taken from 3 $\mathrm{cm}$ above the gastro-oesophageal junction. The presence of any other lesion in the upper gastrointestinal tract was also noted. The oesophageal biopsies were examined for the presence of oesophagitis as assessed by the acute inflammatory cell infiltration. Basal cell hyperplasia and submucosal papillary height were not used in the assessment due to inconsistencies in biopsy orientation.

\section{OESOPHAGEAL MANOMETRY}

This was done in fasted and supine patients who had not taken medication for 48 hours before the investigation. Measurements were done with a triple lumen catheter (external diameter $3.5 \mathrm{~mm}$ ) with each lumen spaced radially at $120^{\circ}$ intervals and longitudinally at $5 \mathrm{~cm}$ intervals. The catheter was perfused with distilled water at a rate of $0.8 \mathrm{ml} / \mathrm{min}$ from a standard low compliance system ${ }^{7}$ connected to transducers and an ink writing polygraph (Grass Model 7D). The lower oesophageal sphincter was identified by the station pull through technique ${ }^{8}$ and its pressure calculated using end expiratory measurement with the gastric baseline as zero reference. Spontaneous activity (more than 1 wave per minute not induced by swallowing) was assessed by leaving the catheter in the distal oesophagus for at least five minutes. Oesophageal peristalsis and its amplitude was assessed by wet swallows ( $5 \mathrm{ml}$ water) at $2 \mathrm{~cm}$ intervals from the lower oesophageal sphincter, atmospheric pressure being used as the zero reference. Particular note was made of the presence of repetitive (three or more peaks induced by a single swallow) and simultaneous waves (greater than $10 \%$ of recorded swallows regarded as abnormal). The upper oesophageal sphincter pressure was taken as the mean of three station pull throughs. Data from each group was compared with a Student's $t$ test.

OESOPHAGEAL PH MONITORING

This was done using a $\mathrm{pH}$ sensitive radiotelemetry capsule and portable receiving equipment (MR 1000 solid state recorder, Oxford Medical Systems Ltd. $)^{9}$ The radiopill was suspended $5 \mathrm{~cm}$ above the proximal end of the previously identified lower oesophageal sphincter by a fine nylon thread taped to the cheek. Signals from the pill were detected by an aerial belt worn around the patients chest and recorded onto the solid state recorded. The studies were carried out over a 24 hour period in which the patients were encouraged to carry on with their normal everyday activities. At the end of the study period the data were played back using a microprocessor controlled playback unit linked to a standard digital printer. This produced an hour by hour record of oesophageal $\mathrm{pH}$ associated with patient triggered events. Analysis was done by observing the frequency and duration of reflux episodes occurring to below $\mathrm{pH} 5$ and $\mathrm{pH} 4$ and calculating the frequency duration index. ${ }^{(1)}$ Comparison of the irritable bowel syndrome patients data was made with that obtained from a group of control patients investigated in the same laboratory. ${ }^{\prime \prime}$

\section{Results}

OESOPHAGEAL SYMPTOMS

Symptoms of gastro-oesophageal reflux (heartburn, acid regurgitation or both), dysphagia and a globus sensation, were significantly commoner in the irritable bowel patients than in the age and sex matched control group (Table 1). In patients with irritable bowel dysphagia (seven women, no men, $\mathrm{p}=(0 \cdot() 12)$ and a globus sensation (seven women, one man, $p=0 \cdot 027$ ) occurred almost exclusively in women.

\section{UPPER GASTROINTESTINAL ENDOSCOPY}

Macroscopic oesophageal disease was found in nine patients; one patient had a Barrett's oesophagus; the remaining eight had oesophagitis which tended to be confined to the distal $2 \mathrm{~cm}$ and noncircumferential; in one patient oesophageal ulceration was present. All macroscopic disease was confirmed on biopsy. Histological examination also showed that a further 11 patients had microscopic oesophagitis; only in five patients was the oesopha-

Table 1 Oesophageal symptoms in patients with the irritable bowel syndrome and a group of age and sex matched controls

\begin{tabular}{|c|c|c|c|}
\hline Symptom & $\begin{array}{l}\text { Irritable } \\
\text { bowel \% } \\
(n=25)\end{array}$ & $\begin{array}{l}\text { Controls \% } \\
(n=150)\end{array}$ & $p$ \\
\hline \multicolumn{4}{|l|}{$\begin{array}{l}\text { Gastro-oesophageal } \\
\text { reflux frequency }\end{array}$} \\
\hline $\begin{array}{l}\text { (a) daily } \\
\text { (b) once a week or }\end{array}$ & 28 & 7 & $<0 \cdot(005$ \\
\hline $\begin{array}{l}\text { or more often } \\
\text { (c) once a month or }\end{array}$ & 52 & 17 & 0.00003 \\
\hline more often & 56 & 26 & $0 \cdot 005$ \\
\hline Dysphagia & 28 & 3 & $0 \cdot 000(2$ \\
\hline Globus sensation & 32 & 5 & $0 \cdot 0006$ \\
\hline
\end{tabular}


Table 2 Lower oesophageal sphincter pressure in patients with the irritable bowel syndrome and an age and sex matched control group

\begin{tabular}{|c|c|c|c|c|}
\hline \multirow[b]{2}{*}{ Group } & \multicolumn{4}{|c|}{$\begin{array}{l}\text { Lower oesophageal sphincter pressure } \\
\text { (mean } \pm S D \text { ) in } \mathrm{cm} \mathrm{H}_{2} \mathrm{O}\end{array}$} \\
\hline & $N$ & $\begin{array}{l}\text { Irritable } \\
\text { bowel }\end{array}$ & Control & $p$ \\
\hline All subjects & 25 & $14 \cdot 0 \pm 5 \cdot 0$ & $19 \cdot 4 \pm 5 \cdot 1$ & $<0 \cdot(0) 1$ \\
\hline Men & 10 & $14 \cdot 1 \pm 5 \cdot 9$ & $19 \cdot 9 \pm 5 \cdot 2$ & $<0 .(05$ \\
\hline Women & 15 & $13 \cdot 9 \pm 5 \cdot()$ & $19 \cdot 0 \pm 5 \cdot 1$ & $<0 \cdot() 1$ \\
\hline $20-40$ years & 18 & $13 \cdot 6 \pm 5 \cdot 4$ & $20 \cdot(0 \pm 5 \cdot 4$ & $<0 \cdot() 1$ \\
\hline $41-60+$ years & 7 & $15 \cdot 0 \pm 5 \cdot 1$ & $18 \cdot(0 \pm 4 \cdot 4$ & NS \\
\hline
\end{tabular}

gus judged to be normal. No patient had a hiatal hernia. Macroscopic gastritis, confirmed on biopsy, was found in six patients.

\section{OESOPHAGEAL MANOMETRY}

The lower oesophageal sphincter pressure was significantly reduced in the irritable bowel patients when compared with the age and sex matched controls (Table 2) but within the irritable bowel group was unrelated to age or sex. There was no difference between the two groups studied in upper oesophageal sphincter pressure or in peristaltic amplitude. Disordered oesophageal peristalsis (spontaneous activity, simultaneous or repetitive waves) was not encountered in the irritable bowel patients.

OESOPHAGEAL PH MONITORING

Data from 22 of the 25 irritable bowel patients was available for the analysis of oesophageal $\mathrm{pH}$. Of the remaining three patients in whom results were not obtained; one regurgitated the pill almost immediately after the start of the test; another refused the investigation and the data from the third was unscorable because of excessive pill $\mathrm{pH}$ drift. The frequency duration index for daytime and night-time recording of reflux episodes occurring to $\mathrm{pH} 4$ or less are shown in the Figure. Ten patients had abnormal reflux detected during daytime recording, four of these also had abnormal night time reflux, making a total of 11 patients $(50 \%)$ in whom abnormality in one or both was found. Lesser abnormalities were present in a further five patients. One patient had abnormal night time reflux detected using the frequency duration index for $\mathrm{pH}$ less than 5 and four more had either abnormally frequent reflux episodes to below pH 5 (2) or had prolonged duration of reflux episodes to below $\mathrm{pH} 4$ (2).

RELATIONSHIP BETWEEN SYMPTOMS AND RESULTS The frequency and severity of reflux symptoms

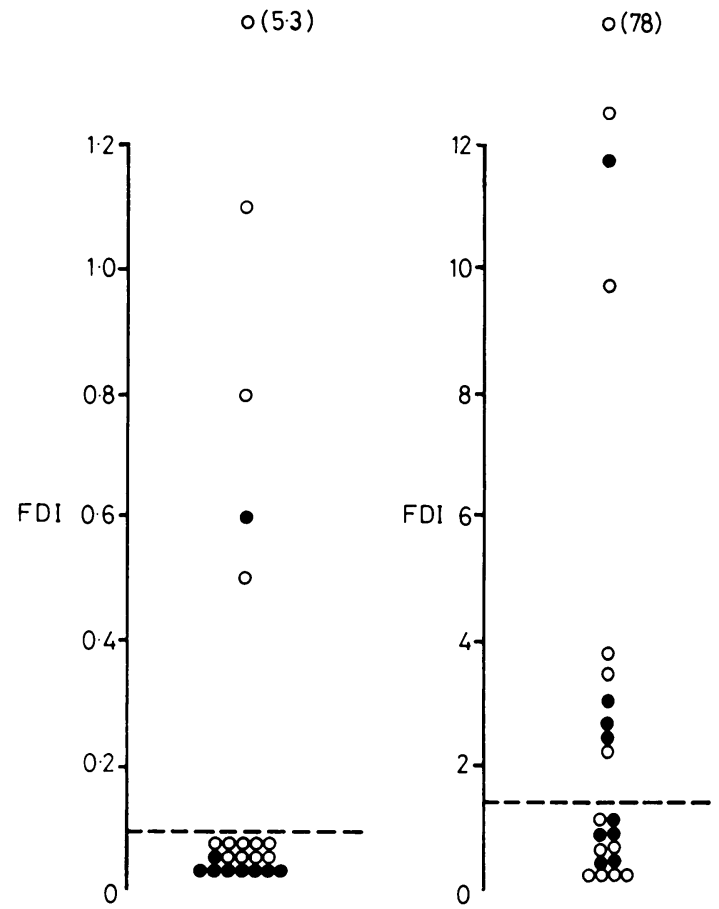

Figure Frequency duration index values for night (left) and day (right) recordings of reflux episodes occurring to pH4 or less. O symptoms of reflux once a month or more often. symptoms of reflux less than once a month. Broken line represents the upper extent of the $95 \%$ confidence limits obtained from a group of normal subjects investigated in our laboratory.

showed no relationship to the severity of oesophagitis or the level of the lower oesophageal sphincter pressure. In those patients with oesophagitis (both macroscopic and microscopic), however, the lower oesophageal sphincter pressure was significantly less $(\mathrm{p}<0.02)$ than those without oesophagitis $(12.7 \pm 4.5$ and $19 \cdot 1 \pm 5 \cdot 2 \mathrm{~cm} \mathrm{H}_{2} \mathrm{O}$ respectively). There was no significant difference in the upper or lower oesophageal sphincter pressure between those patients with or without dysphagia or a globus sensation. Oesophageal $\mathrm{pH}$ monitoring revealed abnormal gastro-oesophageal reflux in 10 of 13 symptomatic patients and four of nine who had infrequent symptoms of reflux (Figure). Of the 17 patients with evidence of oesophagitis at endoscopy, 12 had abnormal reflux as did four of five patients with a normal oesophagus.

\section{Discussion}

Various upper abdominal symptoms have been described in association with irritable bowel and 
these include dyspepsia, heartburn, nausea, bloating, and globus. ${ }^{1-3}$ Watson et al ${ }^{12}$ reported oesophageal symptoms in $51 \%$ of patients with irritable bowel compared with $13 \%$ of those with organic gastrointestinal disease. The present study provides clear confirmation that symptoms referable to the oesophagus are significantly more common in the irritable bowel syndrome than in the general population as represented by fracture clinic patients. Heartburn, acid regurgitation, and globus are the major symptoms, although some would deny that these are more commonly found in the irritable bowel syndrome. ${ }^{13}$ Disagreement exists about the cause of these symptoms; hypertonicity of the upper oesophageal sphincter, ${ }^{14}$ disordered oesophageal motility with frequent non-propulsive contractions and a reduced lower oesophageal sphincter pressure $^{4}$ have been reported. Atrophic and superficial gastritis is a frequent finding in irritable bowel. ${ }^{95}$ The present study confirmed that a significant reduction in lower oesophageal sphincter pressure accompanies the irritable bowel syndrome but no disturbance of oesophageal peristalsis or spontaneous motor activity could be found. There was no obvious correlation between symptoms and manometric abnormality. Although globus was common in our patients it was not associated with an increase in resting upper oesophageal sphincter pressure or with oesophageal motor disorder.

The type of dyspepsia and the reduced lower oesophageal sphincter pressure led us to search for gastro-oesophageal reflux. Ambulatory 24 hour oesophageal $\mathrm{pH}$ monitoring gave unequivocal evidence of abnormal reflux in at least half of our patients. The presence of macroscopic changes of oesophagitis at endoscopy in $36 \%$ of our patients and the histological signs of inflammation in a further $44 \%$ provided additional evidence that gastro-oesophageal reflux was indeed a frequent occurrence in the irritable bowel syndrome. Allowing for the notorious difficulty in the interpretation of mild changes in oesophageal biopsy material, over a third of our patients still had clear cut evidence of oesophagitis.

This study, therefore, clearly indicates that gastro-oesophageal reflux is prevalent in the irritable bowel syndrome and that it is frequently associated with oesophagitis. It seems probable that this is the major cause of the dyspeptic symptoms reported by ourselves and others. We did not take routine gastric mucosal biopsies but in six $(24 \%)$ of our patients macroscopic signs of gastritis were detected, giving a substantially lower incidence than that reported by Fielding and Doyle. ${ }^{15}$

The reason why reflux should be associated with the irritable bowel syndrome is obscure. No charac- teristic pattern of, or consistent abnormality in colonic motor activity has been established in irritable bowel although one study showed excessive slow wave colonic electrical activity. ${ }^{16}$ Abnormality in vagal function has been described in patients with gastro-oesophageal reflux ${ }^{17}$ but whether this is present in the irritable bowel syndrome or could form a common basis for oesophageal and colonic symptoms remains conjectural.

We are grateful to Dr P G Smith for his interpretation of the oesophageal biopsy changes and Dr J A Jones for her help with the manometry and $\mathrm{pH}$ monitoring. We also would like to thank the orthopaedic surgeons in our hospital for allowing us to survey their fracture clinic patients.

\section{References}

1 Watson WC, Sullivan SN, Corke M, Rush D. Globus and headache: common symptoms of the irritable bowel syndrome. Can Med Assoc J 1978; 118: 387-8.

2 Rubin L, Wald A, Schuster MM. Unrecognised common features of irritable bowel syndrome. [Abstract]. Gastroenterology 1979; 76: 1230A.

3 Dotevall G, Svedlund J, Sjodin I. Symptoms in irritable bowel syndrome. Scand J Gastroenterol 1982; 17: suppl. 79: 16-19.

4 Whorwell PJ, Clouter C, Smith CL. Oesophageal motility in the irritable bowel syndrome. $\mathrm{Br}$ Med $\mathrm{J}$ 1981; 1: 1101-2.

5 Kingham JGC, Bown R, Colson R, Clark ML. Jejunal motility in patients with functional abdominal pain. Gut 1984; 25: 375-80.

6 Manning AP, Thompson WG, Heaton KW, Morris AF. Towards positive diagnosis of the irritable bowel. Br Med J 1978; 2: 653-4.

7 Arndorfer RC, Stef JJ, Dodds WJ, Lineham JH, Hogan WJ. Improved infusion system for intraluminal oesophageal manometry. Gastroenterology 1977; 73: 23-7.

8 Hay DJ, Goodall RJR, Temple JG. The reproducibility of the station pull through technique for measuring lower oesophageal sphincter pressure. Br J Surg 1979; 66: 93-7.

9 Evans DF, Jones JA, Hardcastle JD. Ambulatory monitoring of gastro-oesophageal $\mathrm{pH}$ using a radiotelemetry capsule and a new solid state recorder with automated analysis. [Abstract]. Gastroenterology 1985; 88: A1376.

10 Branicki FJ, Evans DF, Jones JA, Ogilvie AL, Atkinson M, Hardcastle JD. The evaluation of oesophageal reflux using a frequency duration index (FDI). Br J Surg 1984; 71: 425-30.

11 Branicki FJ, Evans DF, Ogilvie AL, Atkinson M, Hardcastle JD. Ambulatory monitoring of oesophageal $\mathrm{pH}$ in reflux oesophagitis using a portable radiotelemetry system. Gut 1982; 23: 992-8. 
12 Watson WC, Sullivan SN, Corke M, Rush D. Incidence of oesophageal symptoms in patients with irritable bowel syndromes. [Abstract]. Gut 1976; 17: 827A.

13 Thompson WG, Heaton KW. Heartburn and globus in apparently healthy people. Can Med Assoc J 1982; 126: 46-8.

14 Watson WC, Sullivan SN. Hypertonicity of the circopharyngeal sphincter: a cause of globus sensation. Lancet 1974; 2: 1417.
15 Fielding JF, Doyle GD. The prevalence and significance of gastritis in patients with lower intestinal irritable bowel (irritable colon) syndrome. J Clin Gastroenterol 1982; 4: 507-10.

16 Snape WJ, Carlson GM, Cohen S. Colonic myoelectrical activity in the irritable bowel syndrome. Gastroenterology 1976; 70: 326-30.

17 Ogilvie AL, James PD, Atkinson M. Vagal impairment in reflux oesophagitis. $Q J$ Med 1985; 54: 61-74. 